\title{
A study on the Training of the Practical Ability of Building Electrical Talents under the Background of the Separation of Supervision Management and Assessment
}

\author{
Kan Fenglong* \\ Information and Control Engineering Academy, \\ Shenyang Jianzhu University \\ Shen Yang, China \\ e-mail: arnold0110@sina.com \\ * Corresponding Author \\ Zhang Dongwei \\ School of Information \& Control Engineering \\ Shenyang Jianzhu University \\ Shenyang China \\ Mao Yongming \\ School of Information \& Control Engineering \\ Shenyang Jianzhu University \\ Shenyang China \\ Wang Xin \\ School of Information \& Control Engineering \\ Shenyang Jianzhu University \\ Shenyang China
}

\begin{abstract}
Objective: Promote the management's system actively to meet the need of 《The national medium and long-term education reform and development plan》 Under the background of the development of the University's forces to participate in the running mechanism of the school. Methods: In the following areas, the construction of electrical professional courses, the construction of practical ability, school enterprise cooperation, teaching staff and other aspects is to improve the practical ability of students and enable them adapt to the development of time. Results: The construction of the university in the building of electrical professional undergraduate students in practice ability, innovative spirit and self development in a favorable environment conditions. The training system model of students' practical ability in building electrical specialty is obtained. Conclusion: the construction of electrical engineering professional personnel training quality assurance system, play students' professional advantages, to improve students' ability and quality of social services, effectively improve the quality of personnel training.
\end{abstract}

Keywords- separation of supervision management and assessment; building electrical ; practical ability ; Engineering education; training objectives

\author{
Chen Nan \\ School of Information \& Control Engineering \\ Shenyang Jianzhu University \\ Shenyang China \\ Lü JiuYi \\ School of Information \& Control Engineering \\ Shenyang Jianzhu University \\ Shenyang China \\ Kan Hongliang \\ School of Information \& Control Engineering \\ Shenyang Jianzhu University \\ Shenyang, China \\ Wang Bin \\ Northeastern University at Qinhuangdao \\ Qinhuangdao, China
}


should explore their own characteristics of professional training objectives and effective way, from the training objectives, quality standards, training programs, curriculum content, practice teaching, training methods and other aspects of [4-6].

\section{REQUIREMENTS FOR PRACTICAL ABILITY OF ELECTRICAL SPECIALTY IN ARCHITECTURAL COLLEGES}

School culture orientation of graduates, educational goals, service oriented should focus on the needs of the industry, should contain embody the advantages of running schools of standard features, reflect superior to other colleges, community recognized the advantages of running. Because school standards are based on industry standards, industry standards are based on general standards, therefore, in accordance with the requirements of electrical engineer training objectives, graduates should have the following aspects of the training of the following aspects of knowledge, ability and quality[7-8].

\section{A. The ability of Engineering project design,} implementation, operation and maintenance

First of all, the knowledge and ability of building electrical drawings. Able to identify and evaluate the general electrical engineering design, based on the analysis of the evaluation of its applicability. Knowledge of laws and regulations concerning basic construction, construction, real estate, urban planning, environmental protection and so on.

\section{B. The ability of engineering information acquisition and identification}

Secondly, we should grasp the methods of scientific literature retrieval, data inquiry, and understand the development of electrical engineering discipline. Master the ability to identify and evaluate the current new technology, new process, and determine its applicability according to actual engineering conditions [9-10].

\section{Have an excellent writing skills and communication skills}

Thirdly the need to master a variety of effective oral and written expression skills, as well as listening skills, with the ability to face the interpersonal skills. Have the ability to communicate through the fast and convenient electronic and multimedia. Master a foreign language, have a good ability to read, understand, write a foreign language document and the ability to communicate in a foreign language.

\section{IDEAS ON THE CONSTRUCTION OF ELECTRICAL ENGINEER TRAINING SYSTEM IN THE BUILDING}

The electrical specialty should focus on the personnel training target, according to the new development and new requirements of the construction industry, from the goal of training engineering practice ability. Practical ability training system is given in Fig.1

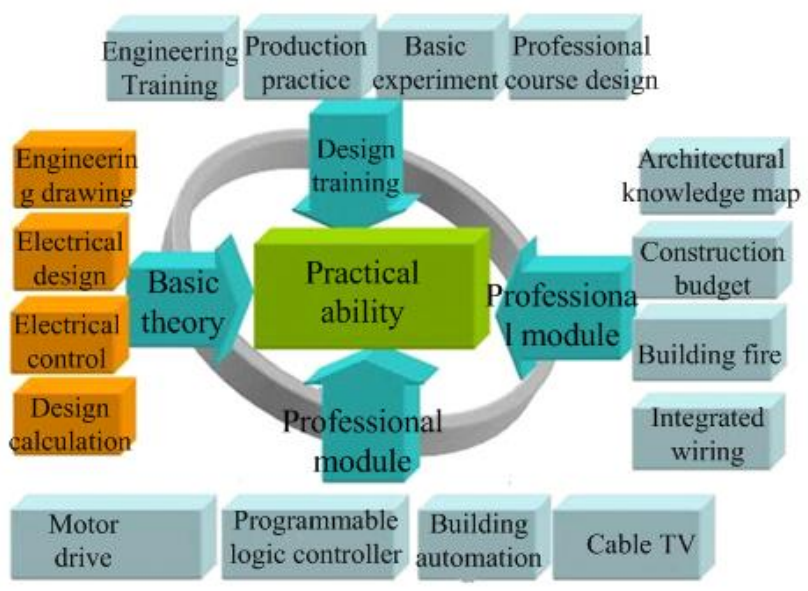

Figure 1. Practical ability training system

A. To establish a curriculum system with perfect and reasonable knowledge structure

Basic courses include electrical engineering and automation of the basic theoretical foundation and ability, such as circuit, analog electronic technology, digital electronic technology, motor and drag, microcontroller principle and application, automatic control theory and other courses and related experiments. The combination of professional courses and industry applications, set up for distribution, building lighting, fire control system, construction and budget, elevator control, so that the students' employment orientation.

B. To increase the interaction between teaching and learning, and to realize the reform of teaching methods and contents

The current student is generally 90 , with a strong sense of self-awareness and good public occasions to express. At the early stage of the project, students can be grouped in the preliminary investigation, each group of students choose a representative to report the results of the survey in a multimedia presentation, you can freely ask questions. Students to introduce their own programs and problems encountered, other students to their program to make their own evaluation and propose solutions to the problem, the teacher should guide in which to promote the full exchange of ideas between students and the solution to the problem.

C. Strengthen teacher's foreign exchange, to do a good job of Teachers Education Strengthen teacher's foreign exchange, to do a good job of Teachers Education

Teachers should understand the development trend of the current society and the needs of the employing units, and strive to introduce the latest and most practical techniques

D. Actively organize innovative activities, enhance students' innovation ability

The students take part in extra-curricular activities of science and technology as an important part of innovative 
education, and effectively improve the students' ability and quality to establish long-term mechanism to promote the students' participation in practical activities. Encourage students to participate in the college students electronic design contest, intelligent building practice skills competition and other kinds of extracurricular science and technology competitions, students practice, hands-on ability, design, drawing ability to get a test, comprehensive use of the ability to get exercise, competition consciousness is enhanced, creative enthusiasm to get further stimulate.

\section{E. Training platform for the construction of students' engineering practice ability}

In the present society, it is required that engineering talents have a solid knowledge and knowledge, but also the use of deep professional knowledge to study and solve social problems. Starting from the goal of training engineering practice ability, the training of electrical professional engineers in building class should be changed to strengthen the practice teaching for a long time..

\section{F. The establishment of a win-win cooperation mechanism between University and society}

At present, the relationship between the University and the enterprise is not close enough, the teaching content of the school and the demand of the enterprise is out of line. Schools and enterprises jointly develop personnel training program, optimize the course content, and the enterprise to build laboratories and R \& D center, to buy or to design and manufacture of equipment similar to the mainstream of the enterprise, to build a practical operating system simulation. In accordance with the production and operation procedures to simulate the operation and training, the reproduction of the production process, strengthen the construction of laboratory.

\section{CONCLUSIONS}

To deepen the reform of education system, to further promote the separation of management and evaluation, and to ensure the independence of the University in teaching, and to make the teachers and students as the center. Adhere to the "quality education" and "practical ability training" concept, based on the industry, ability and social needs as the core, the construction of electrical engineering professional personnel training quality assurance system, play students' professional advantages, to improve students' ability and quality of social services, effectively improve the quality of personnel training.

\section{REFERENCES}

[1] Wei Li ming, Han Cheng hao, Wang Cong ze, "Comprehensive Teaching Reform of Electrical Engineering and Automation Professional Applied Talents," Journal of Jilin Institute of Architecture \& Civil Engineering. Changchun, vol.30, 2013,pp.91-93.

[2] Liang mei, "The research and practice of the construction and management of the application oriented experimental teaching system of Civil Engineering Specialty in private colleges and Universities" Jajrnal Of Chifeng Univesity(Natural science Editim). Chi feng, vol. 29, 2013, pp.211-213.

[3] Chu Fumin, Zhang Guiqing, "T Innovation and practice of the research-based teaching modes emphasizing specialty characteristic:A case study on the electrical specialties" JOU R NAL OF SHANDONG JIANZHU UNIVE R SITY. Jinan, vol. 30 2014,pp.200-204.

[4] Qu Bo, Cheng Zhe, Ma Zhong, "Research and practice of undergraduate teaching model based on autonomous learning and research teaching'Beijing, vol. 30,2011,pp.85-87

[5] Wang Xin, Huang Kuan, Gao Zhijun. The Primary Users' Signals Recognition Algorithm in Cognitive Radio Networks via KPCA and Random Forest[J].ICIC Express Letters,2015, 9(4):10831088.

[6] Cui Liying, "The problems and the existing problems in the implementation of research teaching in Colleges and universities " Journal of Shenyang Institute of Engineering (SOCIAL SCIENCE EDITION), Shenyang,vol31,2010,pp. $132-$ 130

[7] Zhang Yi, often Chunyun, Yang Yingqiang, "Under the condition of information electrical construction of professional teaching resources exploration ," China Electric Power Education.Beijing,vol.30,2011,pp. 61 - 62 .

[8] Huang Tingzhu, Gao Jian, "The reform and practice of research teaching method and test method for college mathematics,"China University Education,Beijing,2012 ,pp. 52 - 55

[9] Wang Xin,Guo Lili,Ma Lina. Cooperative Spectrum Sensing Algorithm Based on Second User Selection and Random Forest Classification[J].ICIC Express Letters, Part B: Applications,2015, 6(3):845-850

[10] Duan Peiyong, "Research on the application of innovative personnel training mode of research ," Journal of Shandong Jianzhu University, Jinan,2012,pp. $444-440$. 